\title{
Recent Advances in Hot Melt Extrusion and Its Applications
}

Ratnaprabha P. Kinikar

ORCID: 0000-0002-9045-406X

Ashwin B. Kuchekar ${ }^{1 *}$

ORCID: 0000-0003-0496-6059

${ }^{1}$ School of Pharmacy, Dr. Vishwanath Karad, MIT WPU, Kothrud, Pune-

411038, Maharashtra, India

Corresponding author:

Ashwin Kuchekar

School of Pharmacy, Dr. Vishwanath Karad, MIT, WPU, Kothrud, Pune-411038, Maharashtra, India

Tel: +91-9420627436

E-mail: ashwin.kuchekar@mitwpu.edu.in

\section{DOI: 10.52794/hujpharm.961794}

\section{ABSTRACT}

Over the decades the outcome of industrial compliance, manufacturing process, formulation and development, Hot Melt Extrusion (HME) also expanded the acceptance. As a result of industrial adaptability, it has developed itself into a wide range pharmaceutical research development. New drug entities face failures or delays during formulation development, including poor biopharmaceutical properties toxicity, lack of efficacy, or both. To overcome such obstacles, the HME technique is preferred one. In comparison to conventional techniques, its use is increasing because of its process, solvent free nature, cost effective, and on-line manufacturing. For achieving different applications, several dosage forms can be produced by altering the design of equipment and adapting a modified processing condition.

Keywords: Hot Melt Extrusion, Screw, Plasticizer, Solubility, Granules 


\section{INTRODUCTION}

Hot melt extrusion (HME) was introduced in the mid-nineteenth century in the plastic industry for the production of plastic bags, sheets, and pipes. After several modifications, special designs and quality of equipment are widely used in the pharmaceutical sector. HME is a process in which raw materials are introduced to an extruder having rotating screws. During the mixing of materials, two forces are generated: one is heat, and the other is shear force. Under these two forces, drugs and other excipients are melted and mixed uniformly to obtain the desired quality. This molten mass is further processed by downstream ancillary equipment to achieve the desired shape and dosage form of the product. Ghalanbor et.al produced implants of thermosensitive proteins or amino acids like Poly(lactic-co-glycolic acid using the HME technique to improve stability. The temperature of the extruder is generally above $\mathrm{Tg}$ (glass transition temperature) and occasionally above the melting point of the polymer. HME technology has been used to create $3 \mathrm{D}$ printed dosage types, taste masking, co-crystals, films, nanotechnology, implants, abuse-deterrent, microencapsulation, semi-solids, gastro-retentive drug delivery systems, the twin-screw granulation technique and solid dispersions. [1-5]

Based on their capacity, pharmaceutical HME is classified into development scale and production scale equipment. For R \& D and clinical purposes, development scale extruders are used in which very less quantities of material are available, while larger quantities of material are needed for production scale. However, complex scenarios such as high temperatures during processing and energy input, shear rates and a lack of HME compatible excipients may have inhibited wider adoption of this technology. Withstanding the above drawbacks, employing innovative techniques such as Quality by Design technique, process analytical technology, and instrument modifications, which include design and geometry of screws, different shapes of dies, as well as the use of suitable additives like swelling agents (sodium starch glycolate), $\mathrm{pH}$ modifiers (Citric acid), foaming agent ( $\mathrm{CO} 2)$, and effervescent agent (Ascorbic acid), they can be overcome. [6-7]

For achieving desirable product quality and a variety of products, HME is used in conjunction with 3D printers as downstream ancillary equipment, as well as pelletizers and high-pressure homogenizers. Improvement in the efficiency of HME is obtained by using a PAT tool and QbD. They can help improve safety, avoid batch losses, and meet requirements. HME may make a major contribution to the on-line manufacturing platform, which is accomplished by optimising particular equipment parameters to manage batch processing limitations. Raman and nearinfrared (NIR) spectroscopy, rheometry and UV/Visible spectrophotometry can provide in-process quality control and an awareness of the extrusion process, achieving high end-product quality. [8-11]

\section{EQUIPMENT DESIGN and PROCESS}

For the first time, El-Egakey et al. looked into hot melt extrusion as a manufacturing apparatus in the pharmaceutical sector. The HME technique consists of a hopper, an extruder, a screw, die or orifice, and ancillary downstream equipment and numerous controlling tools to ensure that the machinery is in good working order and that the extrudates are of the highest possible quality. The entry point of the extruder is a hopper into which raw materials are added. With the help of a single or twin screw, these materials are mixed and conveyed. This extruder comes out of an orifice known as a die, and the desired shape is obtained. There is no need for any die for formulations like co-crystals, salts, microsystems, granules, solid dispersions, semi-solids, or nano systems. [12]

The screws are grouped as single screw extruder (SSE), twin screw extruder (TSE) and multi-screw extruder (MSE) (Table.1). In the plastic industry, SSE is used due to its cost effectiveness and simple equipment design, but not in the pharmaceutical sector due to its poor mixing ability. In the 1930s in Italy, the twin screw extruder was invented. Two agitators are sited on a parallel shaft having co-rotating and counter-rotating screws, i.e., screws rotate in the same direction and different directions, respectively. This screw has two types, i.e., intermeshing and nonintermeshing screws. The gap between the shafts is similar to the diameter of the screw, which is known as a non-intermeshing screw. In contrast to this, in intermeshing screws, the centreline gap between the shafts is much less than the diameter of the screw. As compared to SSE, intermeshing TSE gives improved mixing in a homogenous solid system where the whole API is uniformly dispersed with other excipients. TSE has some silent features like self-cleaning 
capability, shorter residence time, and low heating. Reduced wastage takes place due to the complete draining of material from the barrel, and it is beneficial when API has higher costs. The Multi-screw extruder (MSE) screw number ranges from two to four. Scale of the model for screws of extruder vary from $11-150 \mathrm{~mm}$, with a length of the screw to its outside diameter ratio of 20 to $40: 1$, with $40 \mathrm{~L} / \mathrm{D}$ being the most popular. Screw configuration is an important central element of HME operation in which capacity to convey and blend is considered. The helical screw does not deliver the effective mixing of API. But it is overcome in the case of a mixing screw/bi-lobed kneading where the efficient mixing of material is obtained.[13-15]

While extrusion is regarded as a one-step procedure, the process may be divided into subprocesses for better understanding.

- Material introduced into the extruder by the hopper

- Mixing of materials, discharging, and material extrusion

- Pumping-out through die

- existing raw material into the downstream process

The drug and raw materials are fed into a warmed extruder with dual/single screws and an orifice to create a final product with the desired size and shape. Parameters which are controlled in this process are rate of feeding, speed of screw and barrel tempera- ture, while monitoring parameters are motor load and melt pressure. In the extruder, to obtain a constant amount of material, residence time, and steady shear stress applied to the material, the feeding rate of the materials and speed of the screw should be constant during the operation. The screw speed and feed rate have an effect on the motor load and melt pressure. To extruder screws are firmly fixed, and their special mixing geometry permits high-shear distributed mixing, resulting in the appropriate dispersive and distributive action (Figure 1). Screw speed, melting point, barrel fill, size of particle of materials, screw configurations and residence time are managed and observed in order to achieve a consistent and homogeneous product through the HME process. Various downstream ancillary elements now play a part in the extruded product's finishing, forming, and analysis. Chill rolls, conveyor belts, pelletizers and strand cutters are examples of these. [16-19]

Siyuan Huang et. al. has struggled to extrude heat sensitive drugs such as gliclazide by taking advantage of this benefit to reduce their sensitivity to higher extrusion temperatures and shorter residence times. HME is a versatile method for preparing solid dispersions transdermal, taste-masked preparations, topical products owing to the modifications made by scientists. A large number of patents and research papers have laid out a wider range of processes that could be effectively conducted using HME, contributing to innovative commercial products. The HME has established itself as a technology pioneer in the pharmaceutical industry due to its flexibility and ease of use. [20]

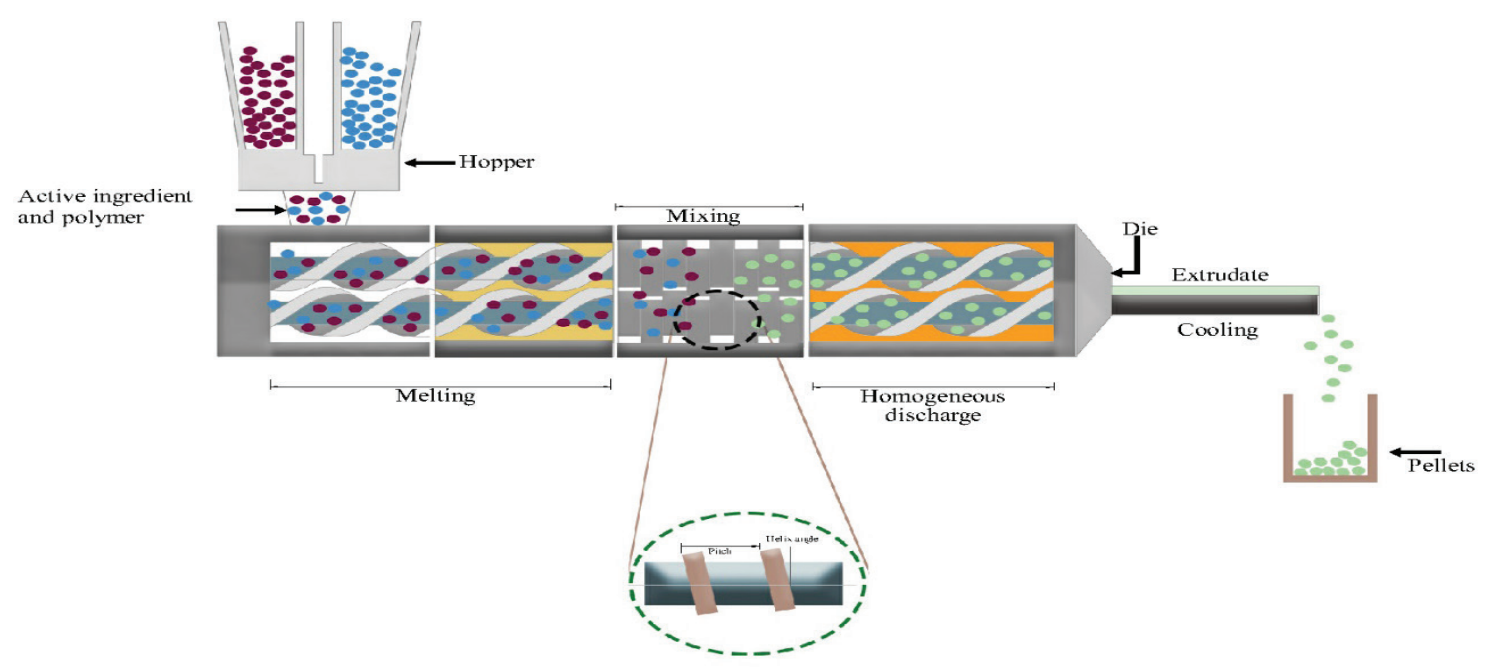

Figure 1. A twin-screw extruder of the HME process 


\section{COMPOSITION OF HME MATERIALS}

A pharmaceutical portion deforms within the heated extruder during HME processing and upon departure it solidifies. All products used in HME should be of equivalent integrity and effectiveness, and they should be free of contamination. For the selection of an API, various drug delivery systems are used, additives and carriers are needed in order for the HME process to run smoothly and continuously in order to obtain the target product. While materials stay within the heated barrel of the equipment for $10 \mathrm{sec}-10$ min (depends on $\mathrm{L} / \mathrm{D}$, design of screw, extruder type, and speed of operation), to minimise the chances of any possible degradation, higher thermal stability requirements will always be appreciated. The use of thermolabile products, on the other hand, is not prohibited by HME.[22]

\section{Carrier}

The selection of a specific carrier must be crucial in the design and preparation of a HME dosage form. The active ingredient is typically coated in a carrier mixture that often contains "meltable" material and additives. The melted material is usually a wax or a polymer with a low melting point. The carrier's physicochemical characteristics will alter the active compound's release from the end product. The compatibility of the active ingredient and the carrier should be considered in systems that use nonpolymeric carrier materials. Eutectic mixture is formed. A compound having a low melting point is added to a wax with a low melting point (MP), or the MP of the mixture is reduced, due to which solid dosage forms are inhibited. The carrier material chosen has a leading effect on the kinetics of drug release from hot-melt extruded formulations. To control the rate of drug release with the aim of covering the granules, waxes and polymers (water insoluble) such as carnauba wax or ethyl cellulose, have been used as carriers in hot-melt extruded dosage types (Table.2). $[23,24]$

\section{Plasticizer}

A plasticizer is a low molecular weight chemical compound that softens polymers and makes them more flexible. The addition of a plasticizer to the formulation throughout the processing of the extruded dosage form in order to advance manufacturing conditions or to improve the final product's mechanical and physical properties. An HME process can be performed with less torque at lower temperatures and with the addition of a plasticizer. Because of the improved manufacturing conditions, both the polymer and the drug product would be more stable during extrusion. Use of plasticizers in the manufacture of dosage forms must be effective, stable, polymer

Table 1. A commercial list of pharmaceutical-grade extruders [21]

\begin{tabular}{|c|c|c|c|c|}
\hline Manufacturer & Extruder & $\begin{array}{l}\text { Diameter of } \\
\text { screw }(\mathrm{mm})\end{array}$ & Capacity* (kg/hr) & Screw type \\
\hline & $\begin{array}{l}\text { Pharma mini HME micro- } \\
\text { compounder }\end{array}$ & Variable diameter & $0.01-0.2$ & $\begin{array}{c}\text { Conical co \& counter } \\
\text { rotating }\end{array}$ \\
\hline & $\begin{array}{l}\text { Pharm } 11 \text { parallel twin screw } \\
\text { compounder }\end{array}$ & 11 & $0.02-2.5$ & $\begin{array}{l}\text { Co-rotating multiple } \\
\text { elements }\end{array}$ \\
\hline \multirow[t]{5}{*}{ Thermo Scientific } & Pharma $16 \mathrm{HME}$ & 16 & $0.2-5$ & \\
\hline & Pharma 24 HME & 24 & $5-20$ & \\
\hline & Pharma 36HME & 36 & $20-100$ & \\
\hline & ZSE 18 HP PH & 18 & $0.5-7$ & Co-rotating \\
\hline & ZSE $27 \mathrm{HP} \mathrm{PH}$ & 27 & $2-60$ & \\
\hline \multicolumn{5}{|l|}{ Leistritz } \\
\hline & ZSE $40 \mathrm{HP} P H$ & 40 & $20-180$ & \\
\hline & ZSE $50 \mathrm{HP}$ PH & 50 & $60-300$ & \\
\hline DSM & $\begin{array}{l}\text { DSM Xplore twin-screw micro- } \\
\text { compound }\end{array}$ & $\begin{array}{l}\text { Different } \\
\text { diameter }\end{array}$ & -- & $\begin{array}{l}\text { Conical co \& counter } \\
\text { rotating }\end{array}$ \\
\hline
\end{tabular}


Table 2. Carriers used in HME [25]

\begin{tabular}{|c|c|c|c|}
\hline Trade Name & Chemical Name & $\mathrm{T}_{\mathrm{g}}\left({ }^{\circ} \mathrm{C}\right)$ & $\mathbf{T}_{\mathrm{m}}\left({ }^{\circ} \mathbf{C}\right)$ \\
\hline Kollidon ${ }^{\circledR}$ & Poly (vinyl pyrrolidone) & 168 & - \\
\hline Avicel® PH 101 & Microcrystalline cellulose & - & - \\
\hline Eudragit $\mathbb{E}$ & Poly (dimethylaminoethylmethacrylate-comethacrylic esters) & 50 & - \\
\hline Sentry ${ }^{\circledR}$ plus & Poly (vinyl acetate) & $35-40$ & - \\
\hline CIBA HI & Epoxy resin containing secondary amine & $80-100$ & - \\
\hline Lunacera ${ }^{\circledR}$ Paracera ${ }^{\circledR}$ & Microcrystalline Wax & - & - \\
\hline
\end{tabular}

plasticizer compatible, and long-lasting. In hot-melt extruded systems, citrate esters, PEG (low molecular weight) and triacetin have been studied as plasticizers (Table.3). Surfactants, in addition to acting as solubilizers, have recently been demonstrated to be powerful plasticizers in the production of solid dispersions by HME. [26,27]

The drug itself will act as a plasticizer on occasion, including ibuprofen (IBP) and chlorpheniramine maleate. In 2002, Brabander characterized the plasticizing property of IBP and found that rising IBP concentrations lowered the glass transition temperature, which specifies the plasticizing effect. Repka (2001) studied that in the case of chlorpheniramine maleate, it acts as a plasticizer along with increasing elongation and lowering tensile strength. [28,29]

\section{Other aids}

Processing unplasticized or under plasticized polymers at high temperatures can cause polymer degradation. Antioxidants, and/or light absorbers may be added to polymers that are prone to degradation during HME to increase their stability. Based on their mechanism, antioxidants are categorised as either chain-breaking antioxidants or preventive antioxidants. Since oxidants, such as ascorbic acid, preferentially undergo oxidation, they can act as a preventative measure against autoxidation. Another form of preventive antioxidant is chelating agents like edetate disodium (EDTA) or citric acid. To make HME processing easier, other materials were used. Waxy materials such as glyceryl monostearate have been documented to serve as a thermal lubricant during hot-melt extrusion. Plasticization of polymers and improved drug absorption have been confirmed with vitamin E TPGS (Table.4). [30]

\section{APPLICATIONS OF HOT MELT EXTRUSION}

Some researchers focused their efforts on evolving dosage forms with the use of hot melt extrusion as an on-line manufacturing technology, and their findings were published. With the advances in conventional drug delivery systems, important growth has been made in the development of novel drug delivery systems based on hot melt extrusion technology.

\section{HME along with three-dimension printing}

Aprecia Pharmaceuticals created the first FDA-approved 3D-printed tablet, Spritam $\AA$, for treating epilepsy seizures. Resin-based 3D systems, extrusionbased systems, droplet-based systems, and powderbased systems are among the 3D printing technologies being investigated for various pharmaceuticals. The material is extruded under pressure in extrusionbased 3D systems, either as a liquid (premixed pastes or inks) or molten mass (heat-assisted). The outline of the extruded filament is $3 \mathrm{D}$ printed. The extrusion-based systems are fused deposition modelling (FDM)/fused filament fabrication (FFF), multiphase jet solidification (MJS), pressure-assisted micro syringes (PAM), and precise-extrusion deposition (PED) (Table 5). [31,32]

The company Stratasys ${ }^{\circledR}$, trademarked FDM, which uses HME to produce filament with preferred properties for 3D printing (Figure 2). In FDM, before being applied layer by layer, a thermoplastic polymer filament is expelled and warmed through a noz- 
Table 3. Plasticizers Used in HME [27]

\begin{tabular}{ll}
\hline Name & Example \\
\hline Fatty acid esters & glycerol monostearate, butyl stearate \\
Phthalate esters & dimethyl, diethyl, dibutyl, dioctyl phthalate \\
Surfactants & polyethylene glycol monostearate, docusate sodium, polysorbates, \\
Citrate esters & tributyl citrate, triethyl citrate, acetyl tributyl citrate, acetyl triethyl citrate, \\
Sebacate esters & dibutyl sebacate \\
\hline
\end{tabular}

Table 4. Aids for processing HME [30]

\begin{tabular}{ll}
\hline Aids & Example \\
\hline Swelling agents & sodium starch glycolate, croscarmellose \\
pH modifiers & Citric acid \\
Foaming agent & $\mathrm{CO}_{2}$ (Pressurized) \\
Antioxidants & BHT, BHA or ascorbic acid \\
Effervescent agent & Sodium Bicarbonate \\
Preservative & Methyl Paraben \\
\hline
\end{tabular}

Table 5. Extrusion based system of 3D printing

\begin{tabular}{cll}
\hline Sr. No & \multicolumn{1}{c}{ Extrusion based system } & \multicolumn{1}{c}{ Specification } \\
\hline 1 & Fused deposition modelling (FDM) & $\begin{array}{l}\text { Heating of filament, Poor Z resolution, Good XY resolution, Low operating cost } \\
\text { and maintenance } \\
\text { 3D printing does not necessitate any prior thermal processing, establish } \\
\text { thermosensitive drug delivery systems, Pressure is used to extrude viscous } \\
\text { semiliquid or paste substance from a syringe. }\end{array}$ \\
& $\begin{array}{l}\text { Pressure-assisted micro syringes } \\
\text { (PAM) }\end{array}$ & $\begin{array}{l}\text { More appropriate than FDM and MJS, no need of filament, Pellets and granules } \\
\text { can be processed }\end{array}$ \\
& Multiphase jet solidification (MJS) & $\begin{array}{l}\text { Extrusion of a melted paste layer by layer through a heated jet nozzle to create a } \\
\text { three-dimensional product }\end{array}$ \\
\hline
\end{tabular}

zle. After each layer is deposited, the build platform moves down, and another layer is deposited on top of the previous layer. As the process progresses, the build platform moves vertically downward while the nozzle moves horizontally. Computer-aided design modelling allows for the formation of virtually any form or geometry object by layering on top of each other (Table 6). [33]

\section{Solid dispersions by HME Solubility/ bioavailability enhancement}

The most well-known applications of HME are the formulation of solid dispersions for the purpose of increasing solubility. By obtaining amorphous shape by crystalline shape of the active ingredient having low solubility by dissolving it in an inert carrier leads to higher solubility of that active ingredient. The amorphous structure has a faster dissolution rate 


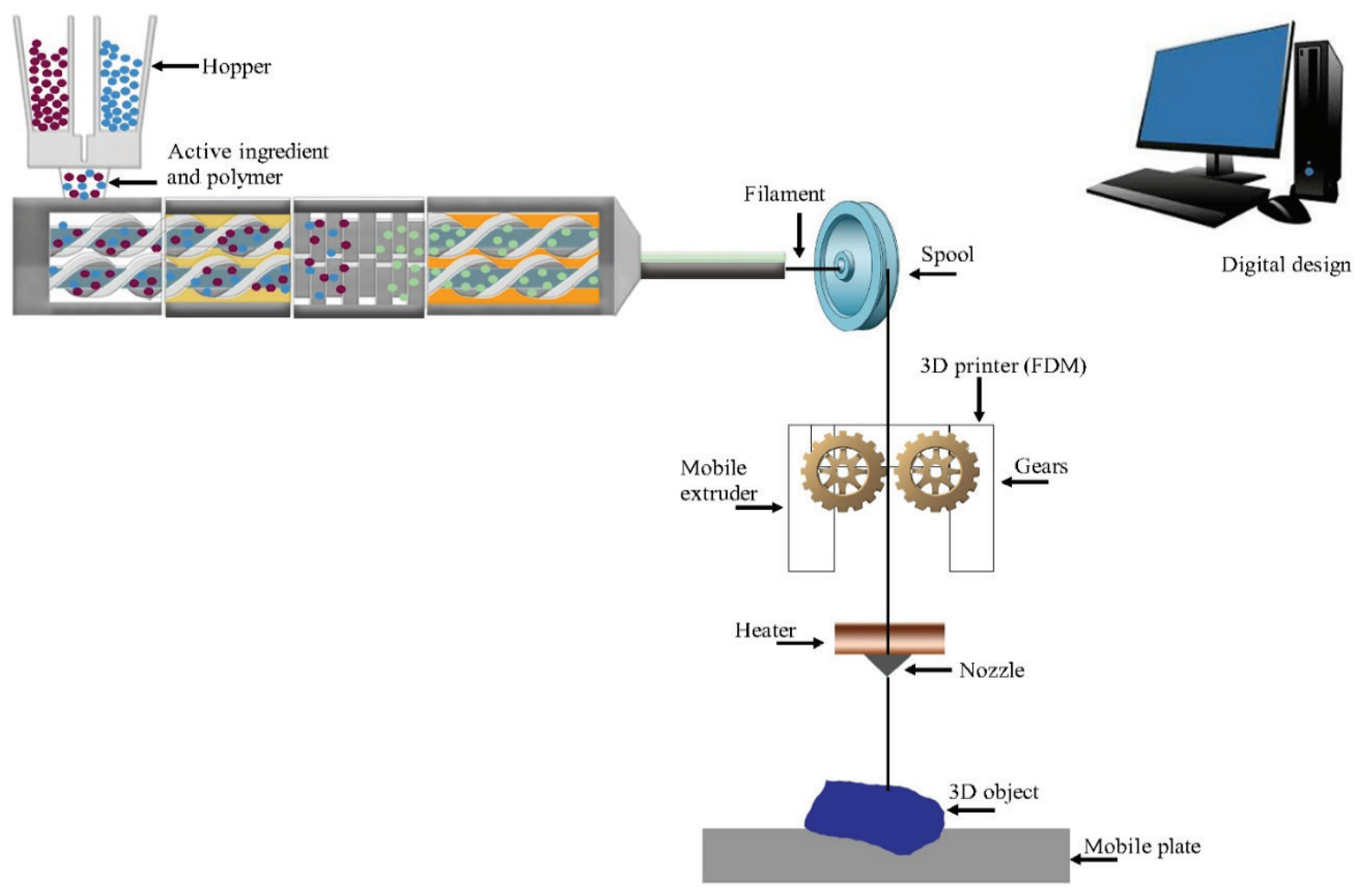

Figure 2. FDM 3D printing with HME

Table 6. Dosage forms developed by 3D printing [33-36]

\begin{tabular}{|c|c|c|c|c|}
\hline Drug & Description & Use & $\begin{array}{c}\text { Temperature } \\
\left({ }^{\circ} \mathbf{C}\right)\end{array}$ & Shape \\
\hline $\begin{array}{l}\text { Aripiprazole BCS } \\
\text { class IV }\end{array}$ & $\begin{array}{l}\text { Films made with a combination of FDM and } \\
\text { HME technology had a positive dissolution rate } \\
\text { and were equivalent to solvent cast films. }\end{array}$ & Antipsychotic & $172{ }^{\circ} \mathrm{C}$ & $\begin{array}{l}\text { Oro-dispersible } \\
\text { films }\end{array}$ \\
\hline $\begin{array}{l}\text { Baclofen BCS } \\
\text { class III }\end{array}$ & $\begin{array}{l}\text { To combat drug errors that result in inadequate } \\
\text { efficacy due to disorganised formulations, a } \\
\text { tailored dosage type for paediatric patients has } \\
\text { been developed. }\end{array}$ & Muscle relaxant & $170{ }^{\circ} \mathrm{C}$ & $\begin{array}{l}\text { Caplet-shaped } \\
\text { (mini) }\end{array}$ \\
\hline $\begin{array}{l}\text { Indomethacin } \\
\text { (IND) BCS class II }\end{array}$ & $\begin{array}{l}\text { HME was used to create paediatric medicines } \\
\text { with enhanced palatability by mimicking } \\
\text { Starmix }{ }^{\circledR} \text { 'candy-like' and sweets printing } \\
\text { formulations using fusion deposition modelling. }\end{array}$ & NSAIDs & $40-120 \circ \mathrm{C}$ & $\begin{array}{l}\text { Various shaped 3D } \\
\text { printed tablet }\end{array}$ \\
\hline $\begin{array}{l}\text { Pramipexole BCS } \\
\text { class I }\end{array}$ & $\begin{array}{l}\text { An IR 3D printed tablet with a small dose (API- } \\
1 \mathrm{mg} \text { ), few inactive ingredients, no need for any } \\
\text { disintegrating agents. }\end{array}$ & Parkinson's disease & $120-130 \circ \mathrm{C}$ & Cylindrical shaped \\
\hline
\end{tabular}

and kinetic solubility can cause supersaturation of the API, increasing the bioavailability of compounds that are badly water soluble in the gastrointestinal fluid. The amorphous substances have greater free energy, which makes them thermodynamically metastable and entropically drives them to a highly stable crystalline state. Rather than using a pure amorphous active ingredient, researchers have attempted to sta- bilise the amorphous shape using other additives, resulting in the formation of amorphous solid dispersions (ASDs) in which composition is made up of a single-phase mixture of active ingredient and stabilising polymers. [37]

Equipment designs, processing conditions and material properties (polymeric carriers and API) are all intertwined in melt-extrusion-produced amorphous 
solid dispersions. In comparison to other traditional techniques such as melt fusion and solvent evaporation, HME technology has proven to be the most effective and efficient method for without the use of solvents in the production of SDs. During the wideranging development of solid dispersions, $\mathrm{QbD}$ techniques and effective design of experiment strategies will assist researchers in achieving consistent quality goods. [38]

Excipients with slow screw speed, lipid excipients (low melting), less moisture content, and a small number of particles were found to be effective in preventing void formation. Using HME technology to treat a variety of ailments, many researchers are actively testing and developing ASDs of various medicaments.

Sarabu et al. also looked into the stability and dissolution of amorphous solid dispersion made with Nifedipine and Efavirenz, the effect of different grades of hypromellose acetate succinate (HPMCAS) using HME technology. Even after three months of stability testing at $75 \%$ relative humidity at $40^{\circ} \mathrm{C}$, the formed ASDs maintained their amorphous existence. With HPMCAS grades, Nifedipine solubilized better than Efavirenz, as per the research.[39]

\section{Abuse-deterrent (AD) drug delivery systems}

To achieve euphoric or sedative effects, one usually takes a higher-than-recommended dose or tampers with the manually manipulating shape or design of a product via a process such as grinding, crushing, or milling. United States regulatory bodies have determined that the dosage form that has been prescribed, especially to treat pain problems such as opioid analgesics used, may be easily abused (nonmedical usage or misuse). Drug abuse can take many forms, including oral, inhalation, nasal, parenteral.

Two of the most popular ways to create AD preparations are raising the tensile strength of a formulation to make it harder to grind/crush, and also making it more viscous so that it prevents IV abuse by adding gelling agents (Figure 3). Additionally, by reducing drug release or inserting unpleasant excipients to make it unsuitable for inhalation, dosages that are less effective or unpleasant may be designed to help avoid drug abuse. Due to its ease of availability, the anti-diarrheal drug Loperamide is often dubbed "poor man's methadone." Many people abuse this drug by taking higher doses, usually higher than 30 pills, to produce a seductive effect or to complete the need of opioid addiction. Nukala et al. used HME to build a loperamide $\mathrm{AD}$ and create a tablet dosage type with polymers (pH-sensitive-Kollicoat ${ }^{\circledR}$, Smartseal 100P, and Eudragit ${ }^{\circledR}$ EPO) and a base (Larginine). The process was done at a 250-rpm screw speed at $150^{\circ} \mathrm{C}$. [40]
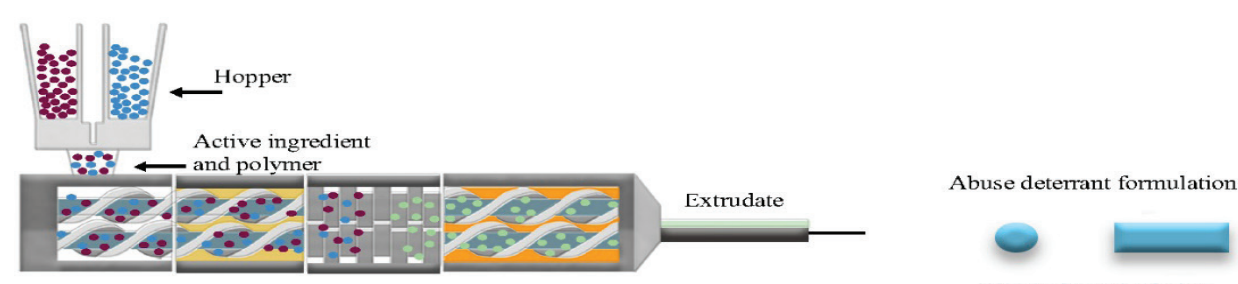

Physical manipulation

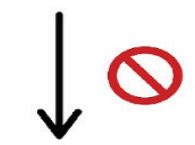

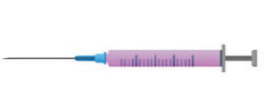

Injection

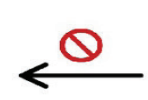

(1)

Figure 3. Methods and routes of abuse drugs and its formulation by HME

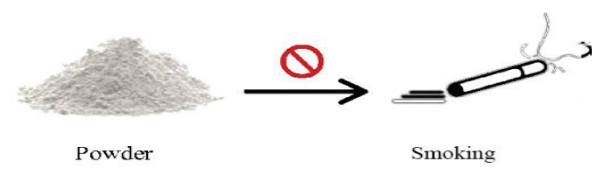




\section{Co-extrusion}

Co-extrudates were made up of two concentrically arranged polymer matrices: a lipophilic centre and a hydrophilic coat. The co-extrusion method involves processing two or more ingredients at the same time via an outlet with two or more orifices, at the end product merging (Figure 4). It is used in bi-layer or multi-layer tablet preparation. Management of two incompatible active ingredients or a changed release mechanism with an outer layer that protects the inner layer can be achieved by HME. [41]

Using an HME technique, Almajaan et al. produced a concentric multi-layered FDC. The aim was to attain different release behaviour from a single dose: Immediate release from the outer layer and Sustain release from the heart, respectively. Antihypertensive medications were selected to be hydrochlorothiazide and losartan potassium. [42]

\section{Shaped drug delivery systems}

When the melted extrudate leaves the extruder, it is formed into the proper cross-section by the extrusion die (flat, annular). The important aspect of the former drug delivery system is the configuration of the orifice that gives the extrudate the optimal configuration, dimension and shape. Shaped drug delivery systems can help monitor drug release by changing the region of the extrudate via geometrical variations (Figure 5).

\subsection{Films}

Thin films are used in a variety of drug delivery systems, including buccal, oral, sublingual, transdermal, ocular and vaginal, and can have both local and systemic effects. Because of their ease of swallowing and self-administering with their rapidly dissolving properties, thin films have emerged as a new drug delivery mechanism. Bio-adhesive films are being produced to increase the product's effectiveness by allowing the drug to be released over a longer period of time. For the production of implants and films, solvent-casting is the most widely used method. [43]

The solvent casting method is advantageous because it is a low-cost continuous process in which solvents are not required. Hot melt extrusion films are made by adding the drug, plasticizer, and film-forming polymer before passing them through a pre-heated hopper and moving them into the barrel (pre-heated) by a revolving screw. The molten state of the polymer, combined with mixing, allows for more uniform fine particle dispersion, which results in the drug's molecular dispersion improving bioavailability. Medicated solvent cast films also face a challenge in terms of drug uniformity.

\subsection{Pellets}

Pellets can be made using HME, in which the material is extruded using a melt pump or an extruder, then pumped through a die, chilled, and diced either

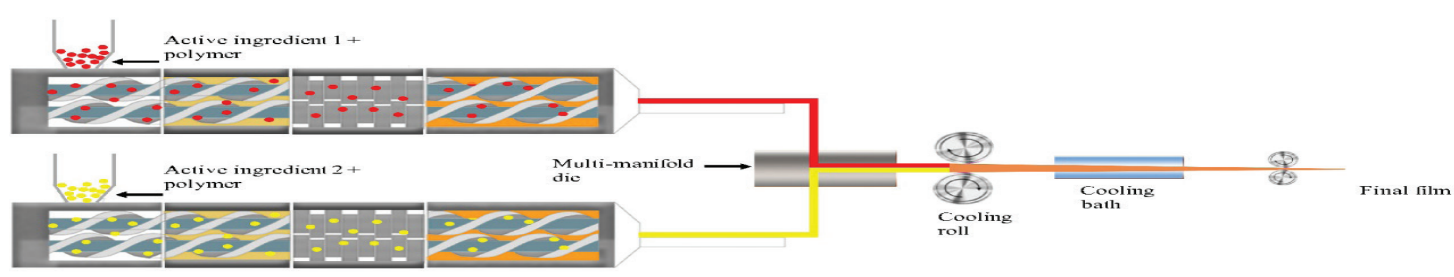

Figure 4. Coextrusion process with HME

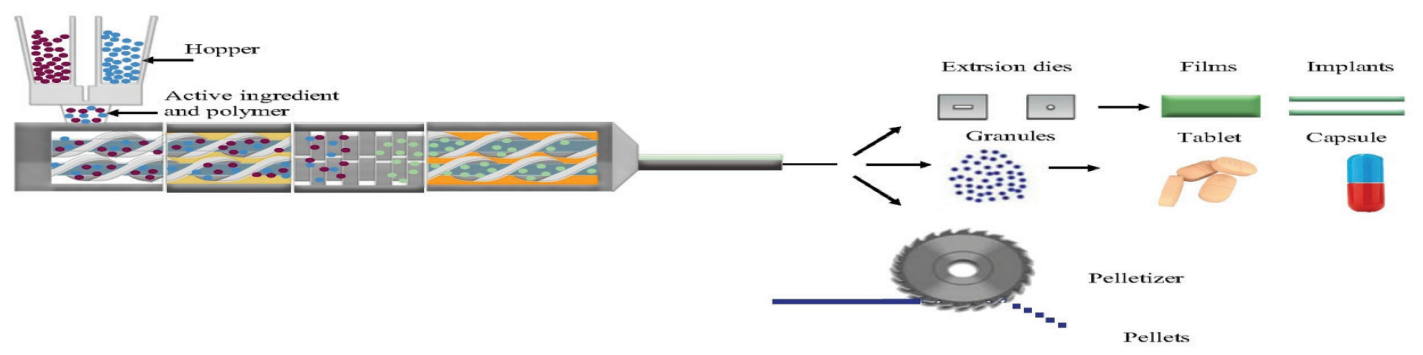

Figure 5. Formulation of various shaped drugs using HME 
manually or with the help of a pelletizer. Pellets may also be used to achieve desired dose strengths without changing the formulation or procedure. These systems have outstanding flow properties as well. The pellet drug delivery system has a number of advantages, including the ability to design and build a reliable oral drug delivery system with a great deal of versatility (suspension, tablet, capsule, sachet). Pellets are often blended with food additives to increase palatability. HME technology makes it simple to process pellets, which can then be further processed with a strand pelletizer. The temperature of the strand pelletizer's inlet and the pelletizer's ingestion speed has an effect on the final pellet consistency. [44]

For the paediatric population, pellets containing diclofenac sodium (Df-Na) were created by Vithani and Douroumis using HME technology to create Compritol ${ }^{\circledR} 888$ ATO. The process was carried out at temperatures ranging from 50 to $75^{\circ} \mathrm{C}$. The use of HME technology to produce high-quality pellets on a continuous basis means that even when a poorly soluble material is used, conventionally prepared pellets must be coated to prevent rapid drug release. HME's pellets are unique in that they're used for either IR or CR applications, based on the characteristics of the matrix polymer. [45]

\subsection{Granules}

Granulation is a particle-to-particle agglomeration process that improves the properties of materials, including tabletability, flowability, and homogenisation for easier management and downstream processing. Due to real-time monitoring, self-cleaning capacity of the screws, simple scalability, improved product consistency, and reproducibility, twin-screw granulation (TSG) is an appealing solution for granulation. Raman and 3D high-speed imaging camera, NIR spectroscopy, spatial filter velocimetry, photometric stereo imaging, and centred beam reflective measurements. For real-time monitoring processing, analytical tools are introduced for the TSG operation. [46]

\subsection{Solid Implant}

"Implantable drug delivery systems" are drug delivery devices that are inserted into the system and release drug (s) for a specific time period at a certain rate. In terms of increased residence time at the specific site, targeted and sustained drug delivery, minimized toxic effects, and abuse-deterrent properties, these systems outperform conventional methods. The ability to control the rate of mass extrusion by changing the extrusion speed and conveyer is a viable technique for obtaining consistent-quality implants. Oral solid dosage types do not face the same difficulties and requirements as implants.

Cosse et al. used HME technology to produce PLGAbased bio-degradable implants including a TSE protein. The chance of high-temperature protein denaturation during the extrusion step is greatly reduced since hot melt extrusion can be handled at minimum temperatures and for a minor time. The processing temperatures (initial- $90^{\circ} \mathrm{C}$ and final- $60^{\circ} \mathrm{C}$ ) were set at $90^{\circ} \mathrm{C}$ and $60^{\circ} \mathrm{C}$, respectively, to obtain effective PLGA workability and minimize thermal stress on the protein. In the extrusion process, both $5 \mathrm{~mm}$ and $9 \mathrm{~mm}$ extruders were used in this study by carefully monitoring the temperature. Novel drug delivery systems with special geometries and release actions can be designed with the help of HME for successful therapy. Using HME technology, effective implants with multiple APIs can be created quickly today. [47]

\section{Semi-solid drug delivery systems}

The development of semi-solids through hot melt extrusion is a less time-consuming and one-step process due to the direct melting and blending of the ingredients. The HME technique used to produce a variety of semisolid products such as creams, ointments, and gels. Mendonsa et. al. developed the poloxamer gel using the HME technique. The end extruded product is free of air bubbles, so no cooling units or de-aerators are needed, as with traditional methods. Since the barrel's screw elements play such a significant role in mixing, no additional scrapers or agitators are needed (Figure 6). The screw components are also important in the size reduction of particles. The high kneading and dispersing process of the mixing material leads to homogeneous distribution of the active ingredient in the melt mix with no lumps of the aqueous and oil phase when the aqueous and oil phases are mixed together. In addition, semi-solid manufacturing operations can be altered by applying different phases to different areas of a barrel to obtain the desired product quality while lowering the retention time for heat-sensitive products. Heat treatments in order to boost dosage stability and enhance the drug's thermodynamic effect on the transdermal membrane. [48-52] 


\section{Microencapsulation}

Microencapsulation is a method of encapsulating, dispersing, or dissolving a drug material (core) within a coating material or matrix. As a result, a physical barrier is formed between the central agent on the inside and the outside atmosphere. The use of HME for drug encapsulation has a number of benefits, including the need for very few to no solvents, which lowers costs. It may also be used to mask the taste of unpleasant APIs and protect sensitive drugs. By enclosing the drug, it is easy to deliver it directly to a specific region, preventing any deterioration or harmful $\mathrm{pH}$ condition system that may interfere with it once it is administered. [53,54]

Using the HME method, Khor et al. produced microcapsules of quercetin by adding excipients such as zein or shellac, carnauba wax, for taste masking. Both microencapsulated formulations (zein, shellac) displayed good taste masking efficiency with carnauba-wax encapsulated powders. Based on the findings, HME microencapsulation may be a promising technique for creating taste-masked products, shielding drugs from the atmosphere. [55]

\section{Self-Micro-emulsifying Drug Delivery Systems (SMEDDS)}

SMEDDS (Self-Microemulsifying Drug Delivery Systems) is an isotropous blend of oils, surfactants, and possibly cosolvents with co-surfactant. SMEDDS are prepared to enhance the solubility of drugs having low soluble drugs. All these materials are introduced into the hopper where they are blended with the help of the screw in the barrel and a mix of SMEDDS is obtained. When these SMEDDS are introduced to an aqueous phase like gastrointestinal fluids, they emulsify into o/w emulsions and form agitations due to gastrointestinal motilities. Liquid SMEDDS have a few disadvantages, such as the need for costly soft gelatine, which leads to oily materials leaching out of the capsules. It may also be prone to chemical instability, resulting in API precipitation. Solid Adsorbing liquid SMEDDS onto a suitable solid carrier yields a free-flowing powder. As a result, solid SMEDDS is a good choice for improved bioavailability and durability, high permeability, easy availability, and precise dosing. [56-58]

\section{Nanotechnology}

Because of its lesser particle size and better dissolution characteristics, nanomedicine has spread into the pharmaceutical industry. It involves extended drug release, decreased repeated dose administration and improved cellular absorption, all of which improve the therapy's efficacy. Traditional approaches often encounter issues such as unreliable batch consistency and a relatively higher cost as a result of the numerous steps involved. To address these difficulties, researchers are turning to HME technology to create oral and topical nano systems that are both healthy for living tissues and possess unique properties. The conventional batch-based approach is still being used to make nanotechnology-based drug delivery systems including nanocrystals, nanostructured lipid carriers (NLC), nanosuspension, solid

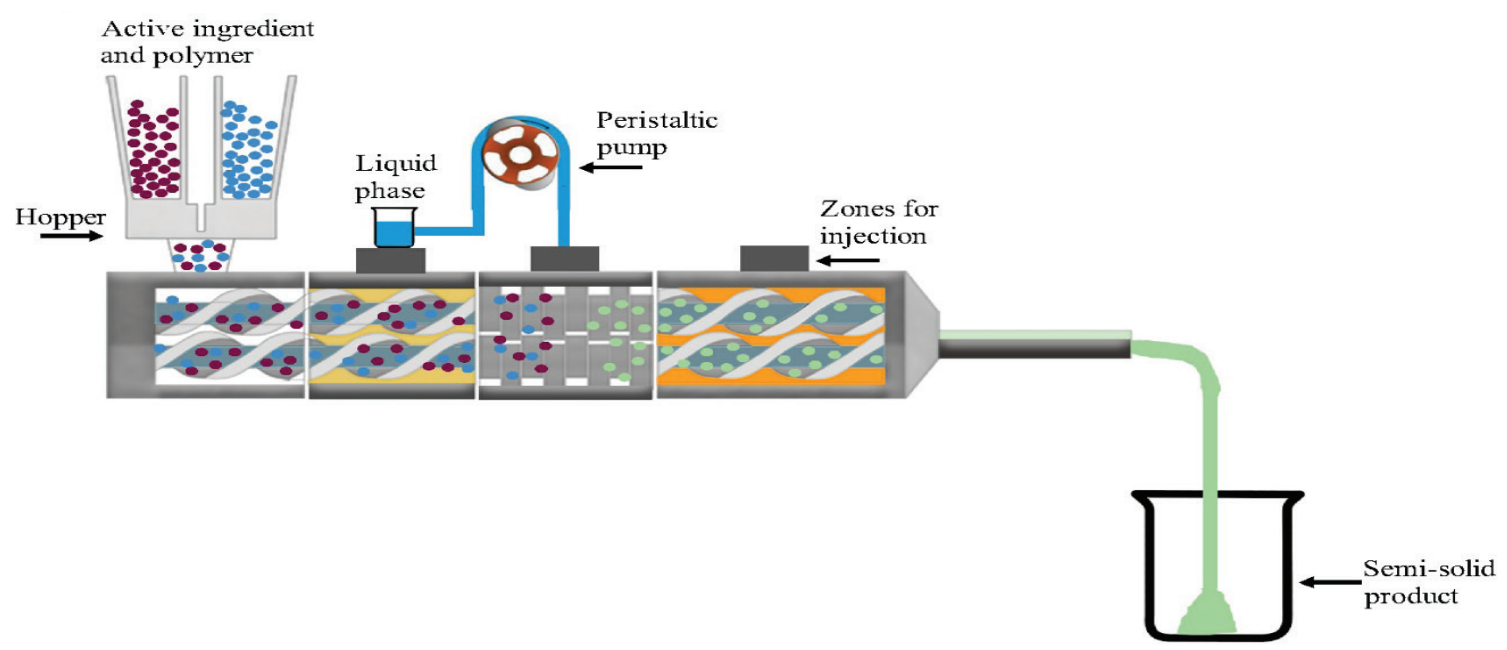

Figure 6. Formulation of Semisolid dosage form using HME 
lipid nanoparticle (SLN) and nano-emulsion. The advanced hot melt extrusion technique is now being used to formulate the aforementioned nano-systems in a unit phase or in combination with a probe sonicator/homogenizer (high-pressure) to further minimise the size of the particles. This technology has proven to be beneficial in the production of nanomedicine because it reduces batch-to-batch inconsistency, cost of production, and processing time. [59-63]

\section{Co-crystallization by $\mathrm{HME}$}

By increasing stability, solubility, and delivery without altering the drug's physiologic functions cocrystals are formed to improve drug bioavailability. The co-crystallization system utilises a biomolecules synthon method, in which a drug's pharmacodynamic and pharmacokinetic properties are altered to improve the drug's poor aqueous solubility. A pharmaceutical co-crystal is made up of two main components: a drug and a co-former. The collaboration between a drug and a co-former is intensified in the HME process due to high shear and vigorous mixing, results in the formation of co-crystals without using solvents. Noncovalent bonds, such as $\mathrm{H}-\mathrm{H}$ bonds, Van der Waals bonds, electrostatic interactions, and halogen bonding are used to interact between the drug and the co-former. [64]

Co-crystals are invented by Fernandes and Rathnanand using hot melt technology to enhance the solubility of carvedilol. A gravimetric screw feeder was used to feed a 1:2 mixture of carvedilol and nicotinamide into the barrel at $20 \mathrm{rpm}$. When hydrophobic carvedilol interacts with nicotinamide, its polarity is increased, which leads to an improvement in its potency. With a speed of $175 \mathrm{rpm}$, the four separate heating regions were set to $32^{\circ}, 85^{\circ}, 90^{\circ}$ and $92^{\circ} \mathrm{C}$ respectively. Co-crystals increased its solubility by 4.79-fold, as equated to pure carvedilol, which was tested during the IV drug release analyses. The cocrystallization method was significantly affected by the processing parameters, which improved when the screw speed and temperature were modified (by fixing the temperature above the eutetic melting point co-crystals are formed). As a result, using $\mathrm{QbD}$ to better understand the effect of HME parameters on co-crystal formation is needed. [65]

\section{CONCLUSION}

Hot melt extrusion has been considered as a feasible solution for the advancement of drug delivery systems, despite being a relatively recent invention in the pharmaceutical sector. Since continuous extrusion is stable and repeatable, conventional batch processes are replaced using single and twin-screw extruders. For solubility improvement, online production, and PAT tools, HME has been widely used. In addition, this "green" technology expense, solvent-free, was presented and evaluated for product viability with 3D printing Fused Deposition Modelling (FDM) applications. In pharmaceutical science, HME has surpassed conventional techniques as a preferred technology for the production of novel drug delivery systems. HME was used to study a variety of drug delivery methods, including oral, parenteral and topical routes. The creation of these novel drug delivery systems was aided by the availability of wide spectrum HME polymers and excipients.

It covers a wide range of endless opportunities and technologies, including 3D printed dosage formulations, co-extrusion, AD formulations, semi-solids, chronotherapeutic drug delivery, nanotechnology, co-crystals, twin-screw granulation, and other uses.

It has some drawbacks, such as limited numbers of excipients are available, it is not suitable for sensitive microbial species, and maintenance of each piece of equipment is required. Since HME allows for the online manufacturing of dosage forms for a wide range of applications, this continuous manufacturing platform provides a real opportunity to address the pharmaceutical industry's crisis. HME, a paradigm-shifting tool, has been used to produce many items previously thought to be outside the reach of this method with only minor equipment and process modifications.

\section{REFERENCES}

1. Cruz CN, Madurawe R, Pavurala N, Chatterjee S. Control strategy considerations for continuous manufacturing using hot melt extrusion, in: I. Ghebre-Sellassie, C. Martin, F. Zhang, J. DiNunzio (Eds.), Pharmaceutical Extrusion Technology, second ed., CRC Press, 2018:53-70.

2. Maniruzzaman M, Nokhodchi A. Continuous manufacturing via hot-melt extrusion and scale up: regulatory matters, Drug Discov. Today 2017; 22:340-351. 
3. M.M. Crowley, F. Zhang, M.A. Repka, S. Thumma, S.B. Upadhye, S.K. Battu, J. W. McGinity, C. Martin, Pharmaceutical applications of hot-melt extrusion: part I, Drug Dev. Ind. Pharm. 33 (9) (2007) 909-926.

4. Cossé, Anne et al. "Hot Melt Extrusion for Sustained Protein Release: Matrix Erosion and In Vitro Release of PLGA-Based Implants." AAPS PharmSciTech vol. 18,1 (2017): 15-26. doi:10.1208/s12249-016-0548-5

5. Z. Ghalanbor, M. Korber, " R. Bodmeier, Improved lysozyme stability and release properties of poly(lactide-co-glycolide) implants prepared by hot-melt extrusion, Pharm. Res. (N. Y.) 27 (2) (2010) 371-379.

6. X. Ye, H. Patil, X. Feng, R.V. Tiwari, J. Lu, A. Gryczke, K. Kolter, N. Langley, S. Majumdar, D. Neupane, Conjugation of hot-melt extrusion with high-pressure homogenization: a novel method of continuously preparing nanocrystal solid dispersions, AAPS PharmSciTech 17 (1) (2016) 78-88.

7. D. Treffer, S. Schrank, Pellet production by hot melt extrusion and die face pelletising, Pharm. Solid State Res. Cluster (2013) 1-5.

8. Arun Butreddy, Suresh Bandari, Michael A. Repka, Qualityby-design in hot melt extrusion based amorphous solid dispersions: An industrial perspective on product development, European Journal of Pharmaceutical Sciences, Volume 158, 2021,105655, https://doi.org/10.1016/j.ejps.2020.105655

9. Marta F. Simões, Rui M.A. Pinto, Sérgio Simões, Hot-melt extrusion in the pharmaceutical industry: toward filing a new drug application,Drug Discovery Today,Volume 24, Issue 9, 2019,Pages 1749-1768, https://doi.org/10.1016/j.drudis.2019.05.013

10. Ashay Manisha Shailendra kumar, Girish Pai Kulyadi, Srinivas Mutalik, Vijay Induvadan Kulkarni, Vamshi Krishna Tippavajhala. Application of Hot Melt Extrusion for the Solubility Enhancement of a BCS Class II Drug. Research J. Pharm. and Tech 2019; 12(8): 3751-3754. doi: 10.5958/0974360X.2019.00642.5

11. M. Stankovi'c, H.W. Frijlink, W.L. Hinrichs, Polymeric formulations for drug release prepared by hot melt extrusion: application and characterization, Drug Discov. Today (2015) 20 (7) $812-823$

12. El-Egakey MA, Soliva M, Speiser P. Hot extruded dosage forms. I. Technology and dissolution kinetics of polymeric matrices, Pharm. Acta Helv. 1971; 46:31.

13. Lawal A, Kalyon D. Mechanisms of mixing in single and Co-rotating twin-screw extruders, Polym. Eng. Sci. 1995; 35:1325-1338. https://doi.org/10.1002/pen.760351702

14. Patil H, Tiwari RV, Repka MA. Hot-melt extrusion: from theory to application in pharmaceutical formulation, AAPS PharmSciTech 2016;17:20-42.
15. Leister D, Geilen T, Geissler T. Twin-screw extruders for pharmaceutical hotmelt extrusion: technology, techniques and practices, in: D. Douroumis (Ed.), HotMelt Extrusion: Pharmaceutical Applications, John Wiley \& Sons, Ltd., 2012;23-42.

16. Martin C. Twin-screw extruders for pharmaceutical products from a technical and historical perspective, in: I. Ghebre-Sellassie, C. Martin, F. Zhang, J. DiNunzio (Eds.), Pharmaceutical Extrusion Technology, CRC Press, 2018; 1-35.

17. Breitenbach J. Melt extrusion: from process to drug delivery technology, Eur. J. Pharm. Biopharm. 2002; 54:107-117.

18. Listro T., Bessemer B., Shape extrusion - extruded implantable drug delivery devices: materials, applications, and processing, in: I. Ghebre-Sellassie, C. E. Martin, F. Zhang, J. DiNunzio (Eds.), Pharmaceutical Extrusion Technology, CRC Press, 2018, pp. 231-246.

19. C.C. Case, A. Huber, K. Nickel, Melt pelletization and size reduction: powder to pellets and powder to powder, in: I. Ghebre-Sellassie, C. Martin, F. Zhang, J. DiNunzio (Eds.), Pharmaceutical Extrusion Technology, second ed., CRC Press, 2018, pp. 183-196.

20. Siyuan Huang, Kevin P. O’Donnell, Sophie M. Delpon de Vaux, John O'Brien, John Stutzman, Robert O. Williams,Processing thermally labile drugs by hot-melt extrusion: The lesson with gliclazide, European Journal of Pharmaceutics and Biopharmaceutics, Volume 119, 2017, 56-67

21. Repka MA, Shah S, Lu J, Maddineni S, Morott J, Patwardhan $\mathrm{K}$, et al. Melt extrusion: process to product. Expert Opin Drug Deliv. 2012;9(1):105-25.

22. R. Steiner, B. Haight, Extruder design, in: I. Ghebre-Sellassie, C. Martin, F. Zhang, J. DiNunzio (Eds.), Pharmaceutical Extrusion Technology, second ed., CRC Press, 2003, pp. 37-52.

23. Miyagawa Y, Okabe T, Yamaguchi Y, Miyajima M, Sato H, Sunada H. Controlled-release of diclofenac sodium from wax matrix granule, Int. J. Pharm. 1996;138: 215-224.

24. Onyechi, J.O. \& Okafo, Sinodukoo. (2015). Evaluation of carnauba wax in sustained release diclofenac sodium tablet formulation. 7. 770-776

25. Repka, Michael A. , "Hot-Melt Extrusion Technology", in Encyclopedia of Pharmaceutical Science and Technology ed. James Swarbrick (Boca Raton: CRC Press, $01 \mathrm{Jul}$ 2013 ), accessed 08 Sep 2021 , Routledge Handbooks Online.

26. Stankovi'c M, Frijlink HW, Hinrichs WL. Polymeric formulations for drug release prepared by hot melt extrusion: application and characterization, Drug Discov. Today 2015; 20: 812-823.

27. Aharoni SM. Increased glass transition temperature in motionally constrained semicrystalline polymers, Polym. Adv. Technol. 1998; 9:169-201. 
28. de Brabander C, van den Mooter G, Vervaet C, Remon J.P. Characterization of ibuprofen as a nontraditional plasticizer of ethyl cellulose, J. Pharm. Sci. 2002; 91:1678-1685. https://doi. org/10.1002/jps.10159

29. Repka, M. A., \& McGinity, J. W. (2001). Influence of Chlorpheniramine Maleate on Topical Hydroxypropylcellulose Films Produced by Hot-Melt Extrusion. Pharmaceutical Development and Technology, 6(3), 297-304. doi:10.1081/pdt100002610

30. Verreck G, Decorte A, Li H, Tomasko D, Arien A, Peeters J, Rombaut P, Van den Mooter G, Brewster ME. The effect of pressurized carbon dioxide as a plasticizer and foaming agent on the hot melt extrusion process and extrudate properties of pharmaceutical polymers, J. Supercrit. Fluids 2006; 38:383391.

31. Zhang J, Vo AQ, Feng X, Bandari S, Repka MA. Pharmaceutical additive manufacturing: a novel tool for complex and personalized drug delivery systems, AAPS PharmSciTech 2018; 19: 3388-3402.

32. Pandey M, Choudhury H, Fern JLC, Kee ATK, Kou J, Jing JLJ, Her HC, Yong HS, Ming HC, Bhattamisra SK, 3D printing for oral drug delivery: a new tool to customize drug delivery, Drug Dev. Transl. Res. 2020; 1-16.

33. Jamroz W, Kurek' M, Łyszczarz E, Szafraniec J, Knapik-Kowalczuk J, Syrek K, Paluch M, Jachowicz R, 3D printed orodispersible films with Aripiprazole, Int. J. Pharm. 2017;533: 413-420.

34. Palekar S, Nukala PK, Mishra SM, Kipping T, Patel K. Application of 3D printing technology and quality by design approach for development of age-appropriate paediatric formulation of baclofen, Int. J. Pharm. 2019; 556:106-116.

35. Scoutaris N, Ross SA, Douroumis D. 3D printed "Starmix" drug loaded dosage forms for paediatric applications, Pharm. Res. (N. Y.) 2018;35:34.

36. Gültekin HE, Tort S, Acartürk F, an effective technology for the development of immediate release solid dosage forms containing low-dose drug: fused deposition modeling 3D printing, Pharm. Res. (N. Y.) 2019;36:128.

37. Gurunath S, Pradeep Kumar S, Basavaraj NK, Patil PA. Amorphous solid dispersion method for improving oral bioavailability of poorly water-soluble drugs, J. Pharm. Res. $2013 ; 6: 476-480$.

38. Butreddy A, Bandari S, Repka MA. Quality-by-design in hot melt extrusion based amorphous solid dispersions: an industrial perspective on product development, Eur. J. Pharmaceut. Sci. 2020; 10:55-56

39. Sarabu S, Kallakunta VR, Bandari S, Batra A, Bi V, Durig T, Zhang F, Repka MA. Hypromellose acetate succinate ba- sed amorphous solid dispersions via hot melt extrusion: effect of drug physicochemical properties, Carbohydr. Polym. 2020;115-828.

40. . Nukala PK, Palekar S, Patki M, Patel K. Abuse deterrent immediate release eggshaped tablet (egglets) using 3D printing technology: quality by design to optimize drug release and extraction, AAPS PharmSciTech 2019;20:80.

41. Vynckier AK, Dierickx L, Voorspoels J, Gonnissen Y, Remon JP, Vervaet C. Hot-melt co-extrusion: requirements, challenges and opportunities for pharmaceutical applications, J. Pharm. Pharmacol. 2013; 66:167-179.

42. Almajaan A, Healy AM, Jones D, Gilvary G, Andrews G, Kelleher J, Li S, Tian Y, Zo'e SL. Hot-melt co-extrusion technology as a manufacturing platform for anti-hypertensive fixeddose combinations, Br. J. Pharmacol. 2019;4

43. Karki S, Kim H, Na SJ, Shin D, Jo K, Lee J. Thin films as an emerging platform for drug delivery, Asian J. Pharm. Sci. 2016;11:559-574.

44. Kayumba PC, Huyghebaert N, Cordella C, Ntawukuliryayo JD, Vervaet C, Remon JP. Quinine sulphate pellets for flexible pediatric drug dosing: formulation development and evaluation of taste-masking efficiency using the electronic tongue, Eur. J. Pharm. Biopharm. 2007; 66:460-465.

45. Vithani K, Douroumis D. Hot-melt extruded lipidic pellets for pediatric applications: an investigation of the effects and stability on drug dissolution, J. Drug Deliv. Sci. Technol. 2019; 49:43-49.

46. Frake P, Greenhalgh D, Grierson SM, Hempenstall JM, Rudd DR. Process control and end-point determination of a fluid bed granulation by application of near infra-red spectroscopy, Int. J. Pharm. 1997;151:75-80.

47. Okumu FW, Cleland JL, Implants and injectables, in: M. Rathbone, J. Hadgraft (Eds.), Modified-Release Drug Delivery Technology, first ed., CRC Press, Boca Raton, 2002, pp. 633-638.

48. Mendonsa, Nicole \& Pradhan, Adwait \& Sharma, Purnendu \& Badani Prado, Rosa Maria \& Murthy, Narasimha \& Kundu, Santanu \& Repka, Michael. (2019). A quality by design approach to develop topical creams via hot-melt extrusion technology. European Journal of Pharmaceutical Sciences. 136. 10.1016/j.ejps.2019.06.002.

49. A.M. Bhagurkar, M. Angamuthu, H. Patil, R.V. Tiwari, A. Maurya, S. M. Hashemnejad, S. Kundu, S.N. Murthy, M.A. Repka, Development of an ointment formulation using hotmelt extrusion technology, AAPS PharmSciTech 2016;17; (1) () 158-166.

50. Mendonsa NS, Pradhan A, Sharma P, Prado RM, Murthy SN, Kundu S, Repka MA. A quality by design approach to develop 
topical creams via hot-melt extrusion technology, Eur. J. Pharmaceut. Sci. 2019; 136:104948.

51. Mendonsa NS, Murthy SN, Hashemnejad SM, Kundu S, Zhang F, Repka MA. Development of poloxamer gel formulations via hot-melt extrusion technology, Int. J. Pharm. 2018 ;537:122-131.

52. Marreto RN, Cardoso G, dos Santos Souza B, Martin-Pastor M, Cunha-Filho M, Taveira SF, Concheiro A, Alvarez-Lorenzo C. Hot melt-extrusion improves the properties of cyclodextrin-based poly (pseudo) rotaxanes for transdermal formulation, Int. J. Pharm. 2020; 119510.

53. Lu Y, Park K. Microencapsulation: methods and pharmaceutical applications, in: fourth ed., in: J. Swarbrick (Ed.), Encyclopedia of Pharmaceutical Science and Technology, vol. 1, CRC Press, Boca Raton (USA), 2012;1-13.

54. Ghosh SK, Functional coatings and microencapsulation: a general perspective, in: S.K. Ghosh (Ed.), Functional Coatings, Wiley-VCH, Weinheim, 2006; 1-28.

55. Khor CM, Ng WK, Kanaujia P, Chan KP, Dong Y. Hot-melt extrusion microencapsulation of quercetin for taste-masking, J. Microencapsul. 2017; 34:29-37.

56. Constantinides PP. Lipid microemulsions for improving drug dissolution and oral absorption: physical and biopharmaceutical aspects, Pharm. Res. (N. Y.) 1995;12:1561-1572.

57. Joyce P, Dening TJ, Meola TR, Schultz HB, Holm R, Thomas N, Prestidge C A. Solidification to improve the biopharmaceutical performance of SEDDS: opportunities and challenges, Adv. Drug Deliv. Rev. 2019; 142:102-117.

58. Luis Antonio D. Silva, Susana L. Almeida, Ellen C.P. Alonso, Priscila B.R. Rocha, Felipe T. Martins, Luís A.P. Freitas, Stephania F. Taveira, Marcilio S.S. Cunha-Filho, Ricardo N. Marreto, Preparation of a solid self-microemulsifying drug delivery system by hot-melt extrusion, International Journal of Pharmaceutics, 2018;541(1-2);1-10
59. Boisseau P, Loubaton B. Nanomedicine, nanotechnology in medicine, C. R. Phys. 2011;12: 620-636.

60. Gajera, Bhavin Y et al. "Investigating a Novel Hot Melt Extrusion-Based Drying Technique to Solidify an Amorphous Nanosuspension Using Design of Experiment Methodology." AAPS PharmSciTech vol. 19,8 (2018): 3778-3790. doi:10.1208/s12249-018-1189-7

61. Ye, Xingyou et al. "Conjugation of Hot-Melt Extrusion with High-Pressure Homogenization: a Novel Method of Continuously Preparing Nanocrystal Solid Dispersions." AAPS PharmSciTech vol. 17,1 (2016): 78-88. doi:10.1208/s12249015-0389-7

62. Gauri Shadambikar, Sushrut Marathe, Nan Ji, Mashan Almutairi, Suresh Bandari, Feng Zhang, Mahavir Chougule, Michael Repka, Formulation development of itraconazole PEGylated nano-lipid carriers for pulmonary aspergillosis using hot-melt extrusion technology,International Journal of Pharmaceutics: X, 2021; 3: 74-100 https://doi.org/10.1016/j. ijpx.2021.100074

63. Patil H, Feng X, Ye X, Majumdar S, Repka MA. Continuous production of fenofibrate solid lipid nanoparticles by hot-melt extrusion technology: a systematic study based on a quality by design approach, AAPS J. 2015;17:194-205.

64. Douroumis D, Ross SA, Nokhodchi A. Advanced methodologies for cocrystal synthesis, Adv. Drug Deliv. Rev. 2017; 117:178-195.

65. Fernandes GJ, Rathnanand M. Formulation optimization for gastroretentive drug delivery system of carvedilol cocrystals using design of experiment, J. Pharm. Innov. 2019; 1-12. 